\title{
Can associative information be strategically separated from item information in word-pair recognition?
}

\author{
JERWEN JOU \\ University of Texas-Pan American, Edinburg, Texas
}

\begin{abstract}
Subjects learned word pairs either once or three times but were instructed to ignore the association of the two words in each pair and only to memorize the individual words at study and recognize them at test. The test word pairs included intact pairs, rearranged pairs made up of old words exchanged among the studied pairs, and new pairs consisting of one old and one new word. Subjects were instructed to respond yes to both intact and rearranged pairs and no to new pairs. Results showed that the rearranged test pairs, as compared with intact pairs, produced longer reaction times, lower discrimination $\left(d^{\prime}\right)$, and lower remember judgments. In addition, more learning either did not reduce or actually increased the pairing effect. These results are difficult to reconcile with the notion that associative information is retrieved in a slow, controlled, and effortful process but are consistent with the encoding specificity principle and the global activation theory of recognition.
\end{abstract}

That contexts can facilitate or hinder remembering of a target item has long been known (Jacoby, Levy, \& Steinbach, 1992; Murnane \& Phelps, 1994; Smith, 1979, 1994; Thomson, 1972; Tulving \& Thomson, 1973; Wickens, 1987). In general, if learning contexts match testing contexts, memory performance for the target item at test is facilitated, whereas when they do not match, memory performance is impaired. This effect is known as the context effect (Murnane \& Phelps, 1994, 1995). The present study examined a particular context effect- that is, pairing words (Thomson, 1972) in word-pair recognition (henceforth, the pairing effect). The focus was on the separability of associative information (the co-occurrence of two words) from item information (the individual words) in recognition and its effects on subjective recollective experiences. A number of studies have shown that recognition memory of single words or word pairs is better if they are tested with the original word contexts than with changed contexts (Humphreys, 1976; Light \& Carter-Sobell, 1970; Thomson, 1972; Tulving \& Thomson, 1973). These findings are consistent with the encoding specificity view (Thomson, 1972; Tulving \& Thomson, 1973) and suggest that changing the paired word in word recognition will depress recognition performance.

However, the issue of the pairing effects in word-pair recognition can be viewed from an alternative perspective. Recognition studies employing a response signal procedure (in which subjects are required to respond at a signaled deadline) and probe foils similar to the targets (e.g., word pairs with rearranged old words) have shown that as the time lag increases, the rate of false alarms to the similar foils first increases but then decreases as the time lag further increases (Dosher, 1984; Gronlund \& Ratcliff, 1989; Hintzman \& Curran, 1994; Light, Patterson, Chung, \& Healy, 2004; Rotello \& Heit, 2000). In word-pair recognition, this result is interpreted as resulting from two stages of processing: an early, familiaritybased, fast, automatic item recognition, followed by a slow, recollection-based, recall-like retrieval of associative information (which is assumed to be required for rejecting the rearranged pairs). Many other studies also have suggested that the retrieval of associative information between two words requires a slow, conscious, effortful process (Hockley \& Consoli, 1999; Meiser, Sattler, \& Weißer, 2008; Westerman, 2001; Xu \& Malmberg, 2007; but see also Cohn \& Moscovitch, 2007). If the retrieval of associative information is indeed a slowly initiated and effortful process, it should be voluntarily inhibitable, and therefore the variation in the pairing of the two words should not affect recognition performance. If associative information cannot be separated from item information, variation on that dimension will either facilitate or impede the decision process concerning the items. If this is so, an intact pair would be expected to produce faster and more accurate recognition than would a rearranged pair. In this study, subjects were required to focus on the relevant item information and ignore the irrelevant associative information (the pairing of the words) both at study and at test. If recognition performance at test is unaffected by the variation in the pairing of words from study to test, the irrelevant dimension is said to be separable from the relevant dimension. If, despite the best effort 
of the subjects to ignore the associative dimension, the test performance is poorer for the rearranged pairs than for the intact pairs, the irrelevant dimension (the associative dimension) is said to be inseparable from the relevant dimension. In that case, it can be argued that the retrieval of associative information might be fast and automatic, rather than slow and effortful.

The impact of variation of the irrelevant dimension on the subjective remembering experience was also examined. The subjective recognition experiences were measured by a remember/know/guess $(\mathrm{R} / \mathrm{K} / \mathrm{G})$ judgment. According to dual-process theories of memory, there are two qualitatively different retrieval processes: a fast, automatic, familiarity-based process and a slow, controlled, effortful, but more accurate, recollection-based process (Atkinson \& Juola, 1973; Hintzman \& Curran, 1994; Jacoby, 1991; Mandler, 1980; Yonelinas, 2002). A remember (henceforth, R) judgment made by subjects to an old recognition is assumed to indicate a recollection-based, episodic memory experience, and a know (henceforth, K) judgment to indicate a familiarity-based experience with few episodic details recollected (Tulving, 1985). If a stimulus feature cannot be separated from the target dimension in recognition, it should be phenomenologically a part of the memory representation. Changing it, therefore, will weaken the sense of a recollection. However, if subjects can cognitively isolate the relevant dimension and define the stimulus as such successfully, then phenomenologically, an intact and a rearranged pair should be judged the same. If, subjectively, this cannot be achieved, the R judgment will be depressed by the change of the pairing context.

A second factor manipulated was presentation frequency (presentation, for short). The purpose of varying the presentation frequency was to test the possibility of selective strengthening of relevant item information in learning over multiple presentations. One possibility is that when given multiple encoding chances, subjects can selectively strengthen item memory without also automatically strengthening the association between the two items. Alternatively, from the viewpoint of the global activation theory (see Murnane \& Phelps, 1994, 1995, for a review), the target items cannot be isolated from the association even with additional learning, and therefore, the pairing effect will persist or even increase as target item memory is enhanced by additional learning.

\section{METHOD}

\section{Subjects}

Seventy-one undergraduate students at the University of TexasPan American participated in the experiment for extra course credit. The data of 1 subject were excluded from analysis for failing to meet the minimum $55 \%$ accuracy criterion $(50 \%$ was chance performance).

\section{Materials, Design, and Procedure}

Eight lists of 24 word pairs each were created for studying. The words were selected from Kučera and Francis's (1967) word frequency norms in the frequency range of 4-10 occurrences per million words. Words were randomly paired. However, care was taken to see that the two words in each pair were not semantically associated and the words across lists not be synonyms or close associates. Of the 24 pairs of test items of a list, 6 pairs were intact, 6 rearranged, and 12 new-item pairs. In the re-pairing, semantic association between the two words in a rearranged pair was avoided as much as possible. The intact and rearranged halves were counterbalanced across subjects. Each new-item pair contained one new word. Half of the new pairs had the new word on the left side, and half on the right side. The new words were selected according to the same principles as the study words. The instruction at the beginning of the study and of the test phases emphasized that the subjects needed only to memorize the two words, but not the pairing or association of the two words, and that which word appeared with which word at study did not matter for the memory test, so they could ignore the pairing of the words at study. At test, the subjects were instructed that if both words were old, regardless of the pairing, they should respond with a yes, and that if one of the two words was new, they should respond with a no.

At study, each pair of words remained in view in the center of the screen, separated by one space for $3.0 \mathrm{sec}$ with a 1 -sec blank screen between the display of one pair and the next. The order of presenting the word pairs within a list and of presenting the lists at study and at test was randomized anew for each subject. Four lists were studied for three rounds, and the other four lists for one round. For the threepresentation lists, a new random presentation order for the 24 word pairs was used for each round of study. The subjects were informed whether a particular list would be studied for one or three rounds before the study of a list began. Between one presentation and the next, the subjects could take a short break; they pressed Enter to start the next presentation or test.

At the end of the study phase, the subjects were asked to count backward by threes for $30 \mathrm{sec}$, starting from a three-digit random number. The subjects responded to the beginning number by typing in the next smaller number and pressing the Enter key. When the subjects gave a wrong number, a warning was displayed along with a beep. In that case, the subjects had to reenter the correct number to continue. When the $30 \mathrm{sec}$ of backward counting expired, the recognition test began. At test, it was emphasized to the subjects that they should respond as quickly and as accurately as they could. The " $\mathrm{z}$ " and "/" keys were the response keys, with the mapping of the keys to the responses counterbalanced across subjects. If participants made a no response, the next test pair was displayed. If they made a yes response, a follow-up judgment about their memory experience was required, in which they made an $\mathrm{R} / \mathrm{K} / \mathrm{G}$ judgment. The reaction time (RT) was the time taken for making the old/new decision in the first decision stage. The meanings of $\mathrm{R}$ and $\mathrm{K}$ were explained, and examples were given to the subjects by modeling Rajaram's (1993) instructions. They chose $\mathrm{G}$ if they could not determine whether they had studied the words and simply made a yes guess. The three number keys " 1 ," "2," and " 3 " on the numerical keyboard were labeled "R," "K," and "G," respectively.

\section{RESULTS}

\section{Analysis of RT Data}

An individual subject's median RT in a condition cell was used as the input data point. The condition RT means were computed from the individual subjects' medians by the statistical analysis program. The mean RTs as a function of presentation and test pair type are presented in Figure 1A.

The RTs for the hits made to the intact and rearranged pairs were analyzed. All the $p$ values in the test statistics were lower than .05 , unless otherwise indicated. An ANOVA using presentation and test pair type (intact vs. rearranged) as two within-subjects factors showed 


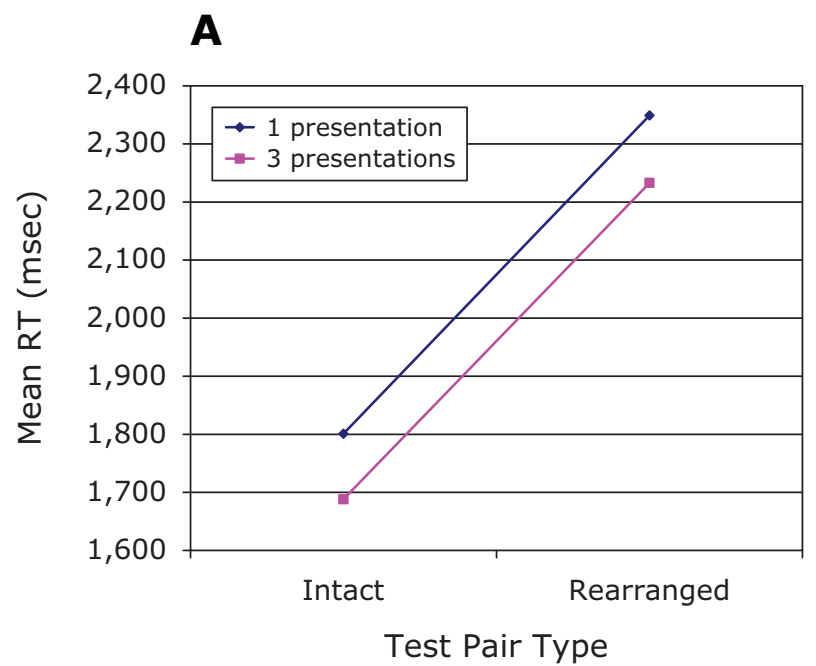

B

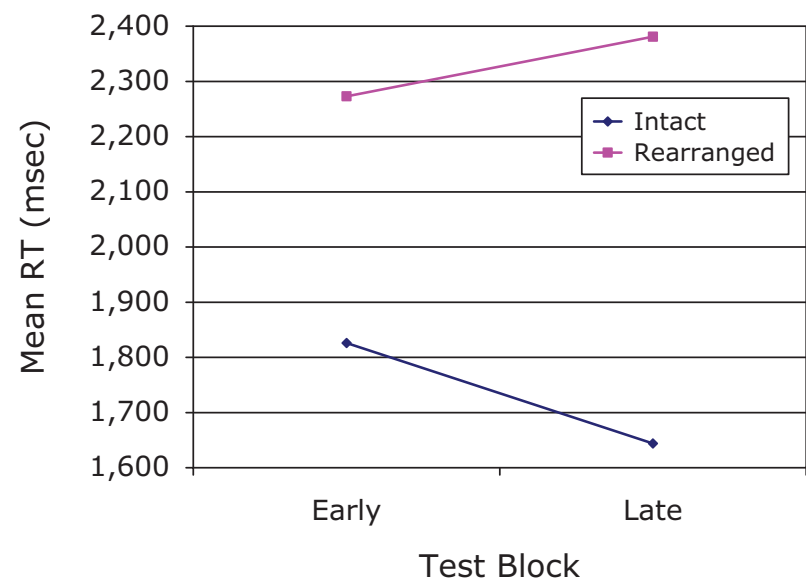

Figure 1. (A) Mean reaction times (RTs) as a function of presentation and test pair type. (B) Mean RTs as a function of test pair type and test block.

that the main effect of presentation was marginally significant $\left[F(1,69)=3.24, M S_{\mathrm{e}}=340,053, p=.07\right]$. The main effect of pair type was significant $[F(1,69)=44.26$, $\left.M S_{\mathrm{e}}=465,854\right]$, indicating a significant pairing effect. The pair type $\times$ presentation interaction was not significant $(F<1)$. Thus, the rearranged pairs produced longer RTs than did the intact pairs, and more learning did not overcome this pairing effect. However, did more testing increase the speed of recognition of the rearranged pairs? To answer this question, the hit RTs for the two pair types in the first two blocks (the early blocks) were compared with those in the last two blocks, Blocks 7 and 8 (the late blocks) in an ANOVA. The mean RTs as a function of pair type and test block are presented in Figure 1B.

The main effect of pair type was significant $[F(1,69)=$ 32.60, $\left.M S_{\mathrm{e}}=735,323\right]$. The main effect of block was not significant $(F<1)$. As is signaled by the diverging lines in Figure $1 \mathrm{~B}$, the pair type $\times$ test block interaction was significant $\left[F(1,62)=5.66, M S_{\mathrm{e}}=215,670\right]$. Hence, not only did more testing not bring down the RT for the rearranged pairs, but it actually increased it (albeit nonsignificantly by a simple-effect test, $F<1$ ), suggesting a very robust pairing effect. A separate ANOVA comparing the mean RTs for R and $\mathrm{K}$ judgments showed that the mean RT for the R judgments $(1,729 \mathrm{msec})$ was significantly shorter than that for the K judgments $(2,642 \mathrm{msec})$ $\left[F(1,68)=85.27, M S_{\mathrm{e}}=339,715\right]$.

\section{Analysis of Discrimination $\left(d^{\prime}\right)$}

The overall hit rate was .70, and the overall false alarm rate was .20 . The mean $d^{\prime}$ s as a function of presentation and pair type are presented in Figure 2.

As was evident, the discrimination level was lower for the rearranged than for the intact pairs. The main effect of presentation was significant $\left[F(1,68)=163.83, M S_{\mathrm{e}}=\right.$ $.269]$, as was that of pair type $\left[F(1,69)=90.79, M S_{\mathrm{e}}=\right.$ .535]. The presentation $\times$ pair type interaction was also significant $\left[F(1,68)=22.71, M S_{\mathrm{e}}=.181\right]$. The interaction indicated that more learning actually increased the pairing effect in discrimination. The $d^{\prime}$ analysis result was consistent with the RT results, in that changing the pairing impaired performance and that more learning either did not overcome or accentuated, rather than attenuated, the pairing effect.

\section{Analysis of Subjective Judgments}

The proportions of $\mathrm{R}, \mathrm{K}$, and $\mathrm{G}$ judgments were calculated according to the assumption that these experiences are mutually exclusive (see Jacoby, Yonelinas, \& Jennings, 1997 , for other ways of measuring the proportion of familiarity experience). The mean proportions of $\mathrm{R}$ judgments as a function of presentation and pair type are presented in Figure 3A.

An ANOVA using the proportion of R judgments, given a hit, showed that the main effect of presentation was significant $\left[F(1,68)=38.28, M S_{\mathrm{e}}=.027\right]$, as was that of pair type $\left[F(1,69)=96.38, M S_{\mathrm{e}}=.041\right]$. The interaction between the two factors was not significant $(F<1)$. It

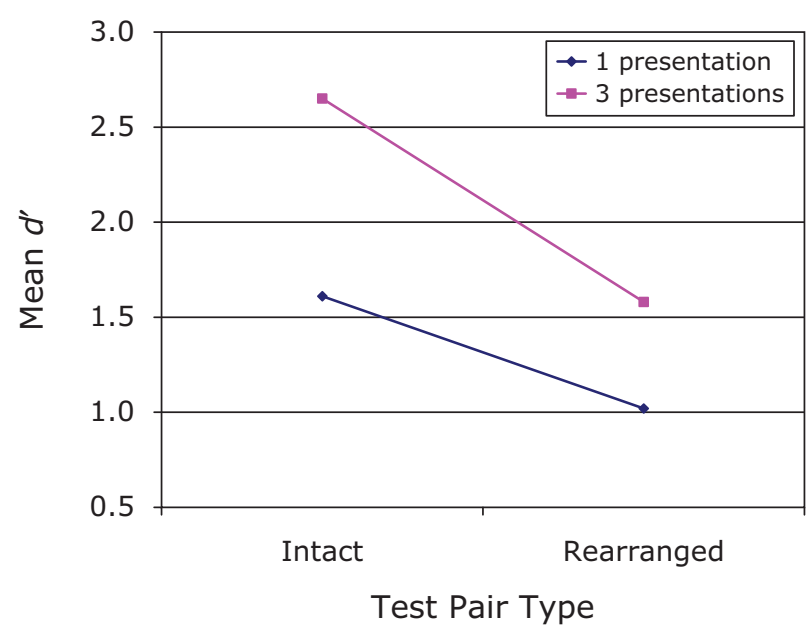

Figure 2. Mean $d^{\prime}$ 's as a function of presentation and test pair type. 


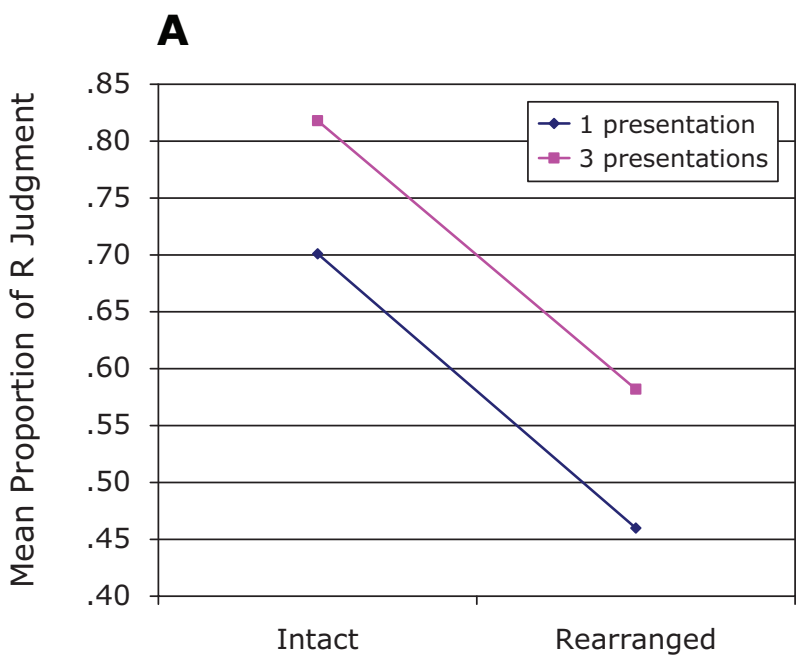

Test Pair Type

\section{B}

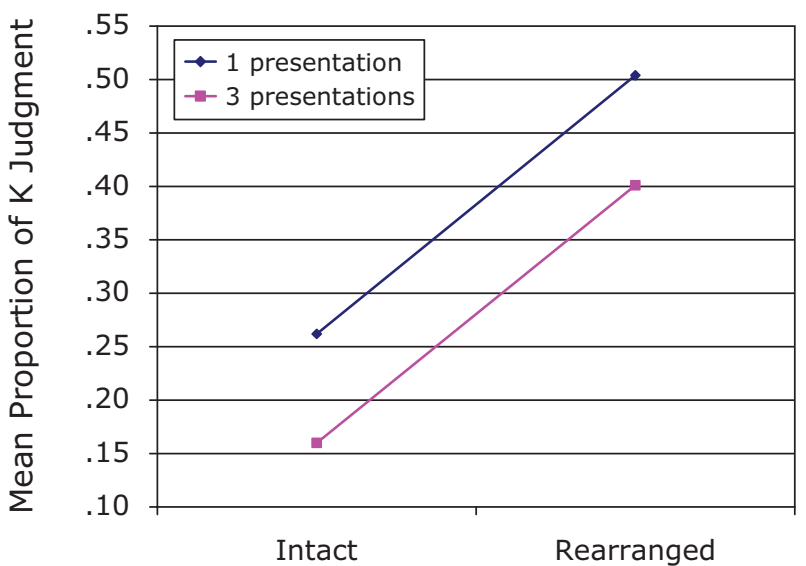

Test Pair Type

Figure 3. (A) Mean remember (R) judgments as a function of presentation and test pair type. (3) Mean know (K) judgments as a function of presentation and test pair type.

was expected that changing the pairing would increase the proportion of $\mathrm{K}$ judgments. The mean proportions of $\mathrm{K}$ judgments as a function of presentation and pair type are presented in Figure 3B.

As can be seen, the rearranged pairs received much higher rates of $\mathrm{K}$ judgments than did the intact pairs. An ANOVA showed that the main effect of presentation was significant $\left[F(1,68)=35.09, M S_{\mathrm{e}}=.022\right]$, as was that of pair type $\left[F(1,69)=87.89, M S_{\mathrm{e}}=.046\right]$. The interaction of these two factors was not significant $(F<1)$. By the recognition criterion defined in the experiment, an intact pair and a rearranged pair were the same, and yet, just as at the objective level (RT and $d^{\prime}$ measures), at the subjective experiential level, the subjects had a much lower recollective impression for the rearranged pairs than for the intact pairs. An ANOVA on the G judgment rate showed only a marginally significant main effect of presentation [mean for one presentation $=.036$; that for three presentations $=$ $\left..020 ; F(1,68)=3.70, M S_{\mathrm{e}}=.005, p=.06\right]$.

\section{DISCUSSION}

As has been noted, most researchers agree that associative memory is the most recollection-based memory process (Clark \& Gronlund, 1996; Hockley \& Consoli, 1999; Westerman, 2001; Xu \& Malmberg, 2007; Yonelinas, 2002) and that a slow, conscious, controlled retrieval mechanism is necessary for associative recognition, although an early-occurring, automatic, familiarity-based process is sufficient for the recognition of two words (Hockley \& Consoli, 1999; Malmberg \& Xu, 2007; Westerman, 2001; Xu \& Malmberg, 2007). If the retrievals of item and associative information are executed in two separate steps and if the retrieval of the latter requires a slow, conscious, effortful mechanism (Gronlund \& Ratcliff, 1989; Hockley \& Consoli, 1999; Meiser et al., 2008; Westerman, 2001; Xu \& Malmberg, 2007), not requiring checking the associative information should make the task easier and faster. The present results showed that the subjects had difficulty achieving the goal of ignoring the associative information, suggesting that the activation of associative information by the item cues may be automatic. Moreover, the slowing down at test in the acceptance of the rearranged pairs was immune to practice, suggesting that the activation of associative information might be highly autonomic.

The lower recognition discrimination $\left(d^{\prime}\right)$ associated with the rearranged pairs indicated that the change in the association could impair the recognition of the items. In addition, when the associative context was changed, the subjective remembering experience was depressed as well, even though the changed pairing was explicitly defined as task irrelevant. Thus, the reduced $\mathrm{R}$ judgments for the rearranged pairs suggested the importance of the association in the memory representation and the phenomenological inseparability of the association from item information.

To summarize, associative information in word-pair recognition seems to be inextricably bound together with item information in an integrated episodic memory trace, and its activation seems autonomic and uninhibitable. These findings are difficult to reconcile with the concept of associative information being retrieved by a postitem, slow, recall-like process (Gronlund \& Ratcliff, 1989; Malmberg \& Xu, 2007; Rotello \& Heit, 2000; Westerman, 2001). They also contradict Hockley and Cristi's (1996) finding that subjects can encode item information and largely ignore associative information (although not the other way around), and Buchler, Light, and Reder's (2008) conclusion that item and associative information are stored and retrieved separately. The present findings are, however, consistent with the encoding specificity principle (Humphreys, 1976; Light \& Carter-Sobell, 1970; Smith, 1979; Thomson, 1972; Tulving \& Thomson, 1973) and support the SAM theory (Gillund \& Shiffrin, 1984; Raaijmakers 
\& Shiffrin, 1981), which postulates that item and associative information are retrieved together and both contribute to overall familiarity in recognition. The finding that increased learning either did not decrease or actually increased the pairing effect (i.e., selective strengthening of targets did not occur) supported the global activation theories (Gillund \& Shiffrin, 1984; Murnane \& Phelps, 1994, 1995). This result further strengthens the conclusion that associative information is very difficult to be separated from item information.

The finding that the supposedly familiarity-based $\mathrm{K}$ judgments were slower than the recollection-based $\mathrm{R}$ judgments, although consistent with reports in the literature (Dewhurst, Holmes, Brandt, \& Dean, 2006; Rotello \& Zeng, 2008), was inconsistent with the dual-process theory of recognition (Yonelinas, 2002). The explanation provided by Yonelinas is that subjects first search for evidence to support the $\mathrm{R}$ response and make a $\mathrm{K}$ response only after they fail to find evidence supporting the R response. Finally, it should be noted that although the pairing effect obtained was compatible with a familiarity-based account of association memory found for unitized pairs of items (e.g., compound words or other stimulus types of integrated pairs; see Diana, Yonelinas, \& Ranganath, 2008; Parks \& Yonelinas, 2008; Quamme, Yonelinas, \& Norman, 2007, for neural evidence for familiarity-based association memory), the word pairs in this experiment were randomly created, and, therefore, the pairing effect was not derived from a semantic unitization of the two words.

\section{AUTHOR NOTE}

I thank Jennifer Tsai for help with data collection and reviewers Bill Hockley, Colleen Parks, and Richard Marsh for helpful comments. Address correspondence to J. Jou, Department of Psychology and Anthropology, University of Texas-Pan American, 1201 West University Drive, Edinburg, TX 78539-2999 (e-mail: jjou@utpa.edu).

Note-Accepted by Cathleen M. Moore's editorial team.

\section{REFERENCES}

AtKinson, R. C., \& JuOLA, J. F. (1973). Factors influencing speed and accuracy of word recognition. In S. Kornblum (Ed.), Attention and performance $I V$ (pp. 583-611). New York: Academic Press.

Buchler, N. G., Light, L. L., \& Reder, L. M. (2008). Memory for items and associations: Distinct representations and processes in associative recognition. Journal of Memory \& Language, 59, 183-199.

Clark, S. E., \& Gronlund, S. D. (1996). Global matching models of recognition memory: How the models match the data. Psychonomic Bulletin \& Review, 3, 37-60.

Conn, M., \& Moscovitch, M. (2007). Dissociating measures of associative memory: Evidence and theoretical implications. Journal of Memory \& Language, 57, 437-454.

Dewhurst, S. A., Holmes, S. J., Brandt, K. R., \& Dean, G. M. (2006). Measuring the speed of the conscious components of recognition memory: Remembering is faster than knowing. Consciousness \& Cognition, 15, 147-162.

Diana, R. A., Yonelinas, A. P., \& Ranganath, C. (2008). The effects of unitization on familiarity-based source memory: Testing a behavioral prediction derived from neuroimaging data. Journal of Experimental Psychology: Learning, Memory, \& Cognition, 34, 730-740.

Dosher, B. A. (1984). Discriminating preexperimental (semantic) from learned (episodic) associations: A speed-accuracy study. Cognitive Psychology, 16, 519-555.
Gillund, G., \& Shiffrin, R. M. (1984). A retrieval model for both recognition and recall. Psychological Review, 91, 1-67.

Gronlund, S. E., \& Ratcliff, R. (1989). Time course of item and associative information: Implications of global memory model. Journal of Experimental Psychology: Learning, Memory, \& Cognition, 15, 846-858.

Hintzman, D. L., \& CuRran, T. (1994). Retrieval dynamics of recognition and frequency judgments: Evidence for separate processes of familiarity and recall. Journal of Memory \& Language, 33, 1-18.

HockLEY, W. E., \& Consoli, A. (1999). Familiarity and recollection in item and associative recognition. Memory \& Cognition, 27, 657-664.

HockLEY, W. E., \& CRISTI, C. (1996). Tests of encoding tradeoffs between item and associative information. Memory \& Cognition, 24 202-216.

HUMPHREYS, M. S. (1976). Relational information and the context effect in recognition memory. Memory \& Cognition, 4, 221-232.

JACOBY, L. L. (1991). A process dissociation framework: Separating automatic from intentional uses of memory. Journal of Memory \& Language, 30, 513-541.

Jacoby, L. L., Levy, B. A., \& SteinbaCh, K. (1992). Episodic transfer and automaticity: Integration of data-driven and conceptually-driven processing in rereading. Journal of Experimental Psychology: Learning, Memory, \& Cognition, 18, 15-24.

JaCOBY, L. L., Yonelinas, A. P., \& Jennings, J. M. (1997). The relation between conscious and unconscious (automatic) influences: A declaration of independence. In J. D. Cohen \& J. W. Schooler (Eds.), Scientific approaches to consciousness (pp. 13-47). Mahwah, NJ: Erlbaum.

KUČERA, H., \& FRANCIS, W. N. (1967). Computational analysis of presentday American English. Providence, RI: Brown University Press.

Light, L. L., \& CARTER-SoBELL, L. (1970). Effects of changed semantic context on recognition memory. Journal of Verbal Learning \& Verbal Behavior, 9, 1-11.

Light, L. L., Patterson, M. M., Chung, C., \& Healy, M. R. (2004). Effects of repetition and response deadline on associative recognition in young and older adults. Memory \& Cognition, 32, 1182-1193.

MalmberG, K. J., \& Xu, J. (2007). On the flexibility and fallibility of associative memory. Memory \& Cognition, 35, 545-556.

MANDLER, G. (1980). Recognizing: The judgment of previous occurrence. Psychological Review, 87, 252-271.

Meiser, T., Sattler, C., \& Weißer, K. (2008). Binding of multidimensional context information as a distinctive characteristic of remember judgments. Journal of Experimental Psychology: Learning, Memory, \& Cognition, 34, 32-49.

Murnane, K., \& Phelps, M. P. (1994). When does a different environmental context make a difference in recognition? A global activation model. Memory \& Cognition, 22, 584-590.

Murnane, K., \& Phelps, M. P. (1995). Effects of changes in relative cue strength on context-dependent recognition. Journal of Experimental Psychology: Learning, Memory, \& Cognition, 21, 158-172.

Parks, C. M., \& Yonelinas, A. P. (2008, November). Familiarity in associative recognition: Influences of modality and time. Poster presented at the 49th Annual Meeting of the Psychonomic Society, Chicago.

Quamme, J. R., Yonelinas, A. P., \& Norman, K. A. (2007). Effect of unitization on associative recognition in amnesia. Hippocampus, 17, 192-200.

RaAiJmakers, J. G., \& Shiffrin, R. M. (1981). Search of associative memory. Psychological Review, 88, 93-134.

RAJARAM, S. (1993). Remembering and knowing: Two means of access to the personal past. Memory \& Cognition, 21, 89-102.

Rotello, C. M., \& Heit, E. (2000). Associative recognition: A case of recall-to-reject processing. Memory \& Cognition, 28, 907-922.

Rotello, C. M., \& ZeNG, M. (2008). Analysis of RT distributions in the remember-know paradigm. Psychonomic Bulletin \& Review, 15, 825-832.

SмITH, S. M. (1979). Remembering in and out of context. Journal of Experimental Psychology: Human Learning \& Memory, 5, 460-471.

Sмiтн, S. M. (1994). Theoretical principles of context-dependent memory. In P. E. Morris \& M. Gruneberg (Eds.), Theoretical aspects of memory (2nd ed., pp. 168-195). London: Routledge.

Thomson, D. M. (1972). Context effects in recognition memory. Journal of Verbal Learning \& Verbal Behavior, 11, 497-511. 
Tulving, E. (1985). Memory and consciousness. Canadian Psychology, 26, 1-12.

Tulving, E., \& Thomson, D. M. (1973). Encoding specificity and retrieval processes in episodic memory. Psychological Review, 80, 352-373.

Westerman, D. L. (2001). The role of familiarity in item recognition, associative recognition, and plurality recognition on self-paced and speeded tests. Journal of Experimental Psychology: Learning, Memory, \& Cognition, 27, 723-732.

WiCKENS, D. D. (1987). The dual meanings of context: Implications for research, theory, and applications. In D. S. Gorfein \& R. R. Hoffman
(Eds.), Memory and learning: The Ebbinghaus centennial conference (pp. 135-152). Hillsdale, NJ: Erlbaum.

Xu, J., \& Malmberg, K. J. (2007). Modeling the effects of verbal and nonverbal pair strength on associative recognition. Memory \& Cognition, 35, 526-544.

Yonelinas, A. P. (2002). The nature of recollection and familiarity: A review of 30 years of research. Journal of Memory \& Language, 46, 441-517.

(Manuscript received January 16, 2010; revision accepted for publication July 17, 2010.) 